\title{
Diabetic myonecrosis, an uncommon presentation of diabetes mellitus in tropical area: a case report
}

Imad Ziryab ${ }^{1}$, Yassin Abdelrahim, Abdalla ${ }^{2}$, Salih Boushra Hamza ${ }^{2}$, Ali Ibrahim Elsiddig Ahmed $^{3}$, Sami Ahmed Abd algadir ${ }^{3}$, and Sohep abdalla osman ${ }^{3}$

${ }^{1}$ University of Bari

${ }^{2}$ Omdurman Islamic University Faculty of Medicine and Health Sciences

${ }^{3}$ Sudan Medical Specialization Board

February 9, 2022

\begin{abstract}
33-year-old Sudanese male patient with type one diabetes presented with progressive, severe bilateral thigh pain with low grade fever. The patient was diagnosed initially as diabetic ketoacidosis with pyomyositis and receive analgesic and insulin the patient partially improved. Diagnosis of diabetic myonecrosis was made based on MRI of the thigh.
\end{abstract}

\section{Hosted file}

myonecrosis2 final report-1.docx available at https://authorea.com/users/459583/articles/ 555811-diabetic-myonecrosis-an-uncommon-presentation-of-diabetes-mellitus-in-tropicalarea-a-case-report 